\title{
RELATOS DE EXPERIENCIA RBEP
}

\section{Educação para sentido na vida e valores: percepção de universitários a partir do livro "Em busca de sentido", de Viktor Frankl*}

David Moises Barreto dos Santos ${ }^{\text {I, II }}$

http://dx.doi.org/10.24109/2176-6681.rbep.100i254.3911

\section{Resumo}

A sensação de vazio e falta de sentido na vida tem se disseminado na sociedade contemporânea, especialmente na juventude. Portanto, se faz necessária uma educação que promova o desenvolvimento pessoal ancorado no sentido de vida, que é compreendido aqui como a motivação primária do ser humano. Para tanto, uma estratégia viável é o uso de expressões literárias, por exemplo, os livros. Desse modo, o objetivo deste trabalho é descrever e discutir a percepção de universitários de engenharia de computação em relação à leitura do livro Em busca de sentido, de Viktor Frankl. Os relatórios produzidos pelos estudantes foram investigados com base na análise de conteúdo. Em geral, os resultados demonstram que os estudantes perceberam a importância de sentido na vida em seu cotidiano e na superação de dificuldades, bem como a liberdade e a responsabilidade que o ser humano tem para escolher (ou não) possibilidades significativas. Ademais, os estudantes mostraram-se satisfeitos com a atividade proposta a partir do livro.

Palavras-chave: educação superior; formação de atitudes e valores; logoterapia.

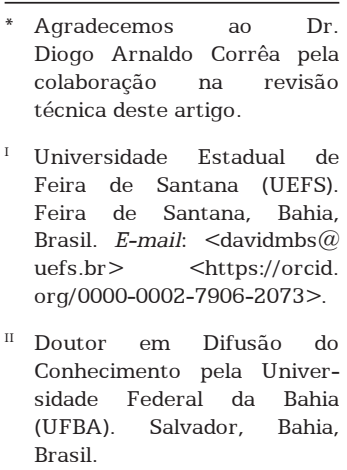
Diogo Arnaldo Corrêa pela colaboração na revisão técnica deste artigo.

Universidade Estadual de Feira de Santana (UEFS). Feira de Santana, Bahia, Brasil. E-mail: <davidmbs@ uefs.br $>\quad<$ https://orcid. org/0000-0002-7906-2073>.

II Doutor em Difusão do Conhecimento pela Universidade Federal da Bahia (UFBA). Salvador, Bahia, Brasil. 


\section{Abstract \\ Education for meaning in life and values: perception of university students from the book "Man's search for meaning" by Viktor Frankl}

A feeling of emptiness and meaninglessness in life has spread in contemporary society, especially among youngsters. Therefore, there is a necessity for an education that promotes a personal development anchored in the meaning of life, that is understood here as a primary source of motivation for human beings. To this end, the use of literature expressions, like books, for example, presents as a viable strategy. Thus, this work describes and discusses the perception of university students of computer engineering on the reading of the book "Man's search for meaning" by Viktor Frankl. Reports written by the students were investigated through content analysis. Overall, the results show that students identify the importance of meaning in life, both in their routines and in the overcoming of hardships, as well as the freedom and responsibility that human beings experience in choosing (or not) meaningful possibilities in life. Additionally, students were pleased with the activity proposed from the book.

Keywords: logotherapy; training for values and stance-taking; higher education.

\section{Resumen \\ Educación para sentido en la vida y valores: percepción de universitarios a partir del libro "El hombre en busca de sentido", de Viktor Frankl}

La sensación de vacío y falta de sentido en la vida se disemina en la sociedad contemporánea, especialmente en la juventud. Por consiguiente, se hace necesaria una educación que promueva el desarrollo personal ancorado en el sentido de la vida, que es comprendido aquí como la motivación primaria del ser humano. Para tanto, una estrategia viable es el uso de expresiones literarias, por ejemplo los libros. De este modo, el objetivo de este trabajo es describir y discutir la percepción de universitarios de ingeniería de computación en relación a la lectura del libro "El hombre en busca de sentido", de Viktor Frankl. Los informes producidos por los estudiantes fueron investigados con base en el análisis de contenido. En general, los resultados demuestran que los estudiantes se dieron cuenta de la importancia de sentido en la vida en su cotidiano y en la superación de dificultades, igualmente la libertad y la responsabilidad que el ser humano tiene para elegir (o no) posibilidades significativas. Además, los estudiantes se mostraron satisfechos con la actividad propuesta a partir del libro.

Palabras clave: educación superior; formación de actitudes y valores; logoterapia 


\section{Introdução}

Viktor Emil Frankl, criador da logoterapia e análise existencial, afirma que a força motriz do ser humano é a presença de sentido na vida. Não se trata, porém, de um sentido único para toda a vida, mas, sim, de um sentido para cada situação que ela apresenta. Por isso, o sentido pode mudar a cada momento e a cada hora. Todas as circunstâncias da vida que uma pessoa vive são dotadas de sentido, até mesmo quando há sofrimento. Isso acontece independente de idade, sexo, escolaridade, profissão e presença - ou não - de uma crença religiosa (Frankl, 2005). Dessa forma, o sentido na vida é a principal motivação do ser humano para amadurecer e superar dificuldades. Quando o ser humano frustra essa vontade de sentido, pode acabar mergulhando em um vácuo existencial, isto é, em um sentimento de vazio e futilidade. Para Frankl, esse é o mal que atinge nossa época, diferentemente do tempo de Freud, em que se padecia da repressão sexual. Em especial, esse vazio apresenta-se de modo mais suscetível entre os jovens e tem sido marcado por uma tríade sintomática: depressão, agressividade e dependência de drogas (Frankl, 2003, 2008).

Desse modo, em uma época marcada pelo vazio existencial, a prática pedagógica também deve ser capaz não apenas de prevenir e combater esse mal, mas também de promover o sentido como força motivadora à pessoa em sua integralidade, o que, inclusive, pode afetar positivamente o aprendizado (Bruzzone, 2011; García, 2009; Miguez, 2014). A motivação humana não está associada apenas a questões biopsíquicas, mas também a convicções e vivências íntimas de que aquilo que se está fazendo é algo verdadeiramente significativo e não hipoteticamente significativo (Bellomo, 2011). A percepção de sentido se dá por meio da consciência, que é o "órgão" do ser humano responsável por distinguir aquilo que tem sentido daquilo que não tem, ou aquilo que tem mais valor ante as possibilidades em cada momento da vida. Assim, o objetivo da educação,

mais do que transmitir tradições e conhecimentos, deveria ser o de refinar a capacidade humana de encontrar sentidos únicos. [...] [A educação] deve, sim, encorajar e desenvolver a capacidade individual da tomada de decisões autênticas e independentes. (Frankl, 2011, p. 84).

Em outras palavras, isso significa investir no aprimoramento da consciência para que seja possível perceber mais possibilidades em um espectro de realidade e, então, escolher aquilo que apresente mais sentido.

Uma estratégia possível é o uso de livros - ou outras expressões literárias, poesias, contos, fábulas etc. - como recurso apelativo da consciência em contextos educativos. Esse tipo de atividade pode favorecer a descoberta de possibilidades e valores, o autoconhecimento, a resolução de problemas, a superação de adversidades, a mudança de atitudes, entre outras competências. Dependerá, naturalmente, de cada pessoa e circunstância, porém o papel do educador aqui é fundamental em relação à orientação adequada da atividade (Del Rio, 2013; Frankl, 1990; Lukas, 2005; Pintos, 1999). 
Nessa perspectiva, o objetivo deste trabalho é descrever e discutir a percepção de graduandos calouros de engenharia de computação em relação à leitura do livro Em busca de sentido: um psicólogo no campo de concentração, do próprio Viktor Frankl. Para tanto, a análise do presente trabalho baseia-se nos relatórios redigidos pelos estudantes sobre o livro. É importante dizer que, notavelmente, as investigações científicas nessa temática têm se concentrado muito mais em questões teóricas (o que é extremamente relevante) do que em propostas práticas, apesar de estas também serem necessárias. Sendo assim, este trabalho almeja contribuir de forma reflexiva para diminuir essa lacuna.

\section{O livro Em busca de sentido}

O livro mencionado pode provocar reflexões acerca da temática em torno do sentido na vida, como já constatado em ocasiões anteriores (Del Rio, 2013; Frankl, 1990). Mais especificamente, essa obra é uma narrativa testemunhal da experiência de Viktor Frankl como prisioneiro comum, número 119.104, que passou por quatro campos de concentração, durante 31 meses e 5 dias (Herrera, 2015). O relato desse livro foi ditado em 1945, pouco mais de sete meses após a sua libertação, durante nove dias e noites consecutivas (Frankl, 2010). A questão que guia a narrativa é a seguinte: "de que modo se refletia, na mente do prisioneiro médio, a vida cotidiana do campo de concentração?" (Frankl, 2008, p. 15). Assim, o autor apresenta um estudo psicológico dos prisioneiros sob a sua ótica, sendo observador e, ao mesmo tempo, objeto de sua prática de observação. Seu relato acaba por corroborar o pensamento de que o sentido de vida constitui a principal motivação do ser humano. Frankl admite que "havia querido simplesmente transmitir ao leitor, através de um exemplo concreto, que a vida tem um sentido potencial sob quaisquer circunstâncias, mesmo as mais miseráveis" (Frankl, 2008, p. 10). De modo mais profundo, o autor procura contribuir para a reumanização da vida e das práticas profissionais, em especial, da prática médica e da psicoterapêutica (Herrera, 2015). Devido a esses aspectos, Gordon Allport afirma que o livro é "uma obra-prima de narrativa dramática, focalizada sobre os mais profundos problemas humanos. Tem méritos literários e filosóficos" (Frankl, 2008, p. 8). Foi traduzido para mais de 25 idiomas e transformou-se em um best-seller em várias partes do mundo. Essas são apenas algumas informações sobre as características e a relevância da obra, o que ajuda a respaldar a escolha para o contexto educativo.

\section{Breve introdução à logoterapia e análise existencial}

Viktor Frankl compreende a pessoa como biopsicossocial e noética. Esta última característica integra as demais e é um princípio de natureza imaterial e transcendente, exclusivo do ser humano, que o diferencia 
dos outros seres vivos. Entre outras coisas, isso significa dizer que o ser humano é orientado por um sentido na vida, é livre e responsável, podendo se autoconfigurar apesar dos condicionantes biológicos, psicológicos e sociológicos. A logoterapia e análise existencial está fundamentada em três conceitos centrais: liberdade da vontade, vontade de sentido e sentido de vida. O primeiro entende que o ser humano é determinado, mas não totalmente determinado, ou seja, ele tem o potencial de decidir como configurar sua história e quais atitudes deve tomar perante os condicionantes existentes. O segundo, vontade de sentido, preconiza uma motivação primária e/ou tendência do ser humano para o sentido na vida ou a busca dele. O terceiro, sentido de vida, não é algo abstrato, mas uma tarefa concreta a ser realizada em uma dada situação. O sentido de vida é incondicional, sempre haverá um para qualquer pessoa e para qualquer situação. Nessa direção, o autor austríaco identificou três grandes categorias em que as pessoas realizam o sentido de vida, resumidas assim: 1) valores de criação, dando algo ao mundo através da sua criatividade, do seu trabalho; 2) valores de vivência, tomando algo do mundo mediante encontros (amando alguém) ou experiências significativas (beleza, natureza, arte etc.); 3) valores de atitude, tomando uma posição perante situações imutáveis de sofrimento, culpa ou morte (tríade trágica). Por fim, é fundamental destacar o caráter autotranscendente do ser humano, o que implica dizer que um sentido de vida é encontrado sempre no mundo, quando o indivíduo se dedica a alguém ou a uma causa (Frankl, 2003, 2008, 2011).

\section{Metodologia}

\section{Sujeitos}

A população que participou desta pesquisa, oriunda de cinco turmas, entre 2015 e 2017, foi composta de 177 sujeitos ao todo - 155 homens $(87,6 \%)$ e 22 mulheres (12,4\%). Todos estavam matriculados no componente curricular Tópicos de Formação Humanística, do primeiro semestre do curso de engenharia de computação da Universidade Estadual de Feira de Santana (UEFS). Em geral, um calouro desse curso tem entre 17 e 18 anos.

\section{Instrumentos}

Os instrumentos utilizados foram:

- Relatório de leitura: atividade pedagógica proposta com base na leitura do livro Em busca de sentido: um psicólogo no campo de concentração, considerando apenas a primeira parte referente à narração sobre os campos de concentração. O relatório a ser elaborado foi orientado de acordo com três questões: 1) Quais as ideias principais do livro?; 2) O que mais chamou a atenção na leitura?; e 3) Em que o livro mais contribuiu para o seu aprendizado 
de vida? Para cada uma dessas duas últimas questões, foi solicitado aos estudantes que apontassem três aspectos, pelo menos, como uma frase, um acontecimento, uma ideia etc., ou seja, algo presente no texto. Os estudantes eram, ainda, estimulados a debater criticamente as ideias do autor, bem como articulá-las com sua vida e sua realidade, inclusive universitária.

- Questionário de avaliação da disciplina: entre outras questões, a atividade relacionada ao livro é avaliada a partir de três questionamentos: 1) Quanto a atividade sobre o livro Em busca de sentido contribuiu para o seu ensino-aprendizagem e/ou foi importante para você?; 2) Quanto você gostou do livro Em busca de sentido; e 3) Quanto você leu do livro mencionado? As respostas das duas primeiras questões estavam dispostas em uma escala de Likert para avaliar atitudes, considerando cinco pontos entre 1 e 5, em que 1 é nada e 5 é muito. A resposta do terceiro item tinha seis opções: não li (0\%), li 20\% aproximadamente, li 40\% aproximadamente, li 60\% aproximadamente, 80\% aproximadamente, li o texto na íntegra (100\%). Esse último item, no entanto, foi aplicado apenas nas duas últimas turmas, sempre no final do semestre.

\section{Procedimento}

A atividade foi proposta no início do semestre e teve um prazo de 3 a 4 semanas para a sua conclusão. Em determinada aula, previamente combinada, os estudantes debateram suas percepções e depois entregaram o relatório para correção e posterior feedback. Nas aulas subsequentes, temas relacionados ao livro - como liberdade, responsabilidades e valores - foram aprofundados através de debates e dinâmicas, porém, o foco desse trabalho se deteve, essencialmente, aos relatórios. Por questões éticas, os nomes dos estudantes foram removidos antes da análise. A avaliação da disciplina foi realizada on-line e de maneira anônima ao final do semestre. A participação foi facultativa. A pesquisa foi aprovada pelo comitê de ética da UEFS.

\section{Análise}

A análise das respostas do questionário foi realizada por meio da análise de conteúdo (Bardin, 2000), com apoio do software NVivo 10. As respostas foram codificadas mediante categorias pré-definidas, principalmente, com base em conceitos da logoterapia e análise existencial. Porém, o sistema de categorias foi revisado sempre que necessário. Um pesquisador codificou todo o corpus de análise, enquanto outro realizou uma revisão de tal codificação. Dúvidas foram discutidas para que se chegasse a uma solução. 


\section{Resultados}

Nesta seção, são apresentadas as percepções dos estudantes acerca das questões trabalhadas nos relatórios. Para uma melhor compreensão, organizamos as três primeiras subseções de acordo com as questões mencionadas. A última subseção tratará de outras análises paralelas aos relatórios e da avaliação da disciplina. É importante esclarecer ainda que as categorias, para cada questão, não foram exploradas exaustivamente por limites de espaço. Portanto, foram apresentadas apenas aquelas mais comentadas pelos sujeitos.

\section{Ideias principais do livro}

A Tabela 1 apresenta as principais categorias entendidas pelos estudantes como mensagens centrais do livro. As frequências absoluta e relativa (em relação ao número total de sujeitos) estão sinalizadas nas colunas FrA e FrR. Além disso, alguns excertos dos relatos estudantis estão listados na coluna exemplo. Os códigos, após os excertos, referem-se aos sujeitos, que foram identificados desse modo com o intuito de manter o anonimato.

Tabela 1 - Categorias de ideias centrais (continua)

\begin{tabular}{|c|c|c|c|}
\hline Categoria & FrA & FrR & Exemplo \\
\hline $\begin{array}{l}\text { Sentido de } \\
\text { vida }\end{array}$ & 95 & $53,7 \%$ & $\begin{array}{l}\text { Viktor Frankl concentra o sentido da vida como } \\
\text { uma principal força motivadora, anexando essa } \\
\text { como a razão para muitos prisioneiros não } \\
\text { desistirem de que um dia possam ser livres } \\
\text { novamente, e tentarem, mesmo com tudo o que } \\
\text { tinham passado, viver. (g24) } \\
\text { A vida sempre tem um objetivo, um sentido, } \\
\text { mas só você pode definir qual e como pretende } \\
\text { alcançar esse sentido. (g22) } \\
\text { E para tentar se manter vivo, pelo menos } \\
\text { espiritualmente, utilizava uma estratégia, talvez } \\
\text { a mais importante, de buscar um sentido para } \\
\text { seu sofrimento, se fixando no futuro, em algo } \\
\text { ou alguém que deixou fora do campo e que está } \\
\text { a sua espera. (e31) }\end{array}$ \\
\hline $\begin{array}{l}\text { Ênfase na } \\
\text { questão } \\
\text { psicológica }\end{array}$ & 61 & $34,5 \%$ & $\begin{array}{l}\text { Aborda os aspectos psicológicos da vida } \\
\text { nos campos de concentração, no período da } \\
\text { segunda guerra mundial, em que relata as } \\
\text { diferentes reações a situações adversas e } \\
\text { condições desumanas em que encontravam-se } \\
\text { os prisioneiros. (d15) } \\
\text { O autor, que também é psicólogo, faz uma } \\
\text { abordagem psicológica, descrevendo seus } \\
\text { sentimentos eobservando seus comportamentos, } \\
\text { pensamentos e atitudes bem como das outras } \\
\text { pessoas que fazem parte da obra. (e29) }\end{array}$ \\
\hline
\end{tabular}


Tabela 1 - Categorias de ideias centrais

\begin{tabular}{|c|c|c|c|}
\hline Categoria & FrA & FrR & Exemplo \\
\hline $\begin{array}{l}\text { Cotidiano } \\
\text { prisional }\end{array}$ & 44 & $24,9 \%$ & $\begin{array}{l}\text { Mostrar ao leitor parte do que se passava } \\
\text { diariamente com os homens que eram } \\
\text { submetidos a situações e condições degradantes. } \\
\text { (d19) } \\
\text { Retratar como era o dia a dia dos prisioneiros } \\
\text { de um campo de concentração. (f35) }\end{array}$ \\
\hline Logoterapia & 35 & $19,8 \%$ & $\begin{array}{l}\text { Viktor também utilizou o livro para divulgar o } \\
\text { método de tratamento psicológico desenvolvido } \\
\text { por ele. (f30) } \\
\text { A experiência o levou a descoberta da logo- } \\
\text { terapia. (a4) }\end{array}$ \\
\hline
\end{tabular}

Fonte: Elaboração própria.

A categoria mais comentada foi "sentido de vida" (por 95 sujeitos), o que representa pouco mais da metade dos sujeitos (53,7\%). Essa categoria retratou: 1) a vontade de sentido como principal motivação do ser humano; e 2) o sentido de vida, quando, com frequência, foi afirmado que ele está presente em qualquer situação, mesmo no sofrimento. Desse modo, os estudantes perceberam o sentido de vida como importante fator de proteção em qualquer situação, até mesmo no sofrimento e no campo de concentração. A análise psicológica de si e dos outros, feita pelo autor, foi comentada por $34,5 \%$ dos sujeitos, enquanto que o relato do cotidiano de um prisioneiro comum no campo de concentração, retratando os horrores do dia a dia, foi comentado por $25 \%$ deles.

Um quinto dos estudantes destacou a logoterapia. Com relação a esse último item, percebeu-se que os estudantes referiam-se ao prefácio do livro, escrito por Gordon Allport, em que é afirmado que "Dr. Frankl descreve a experiência que o levou à descoberta da Logoterapia" (Allport, 2008, p. 5). Na verdade, essa informação está equivocada e os leitores acabam propagando tal equívoco. Frankl (2010) já vinha esboçando sua teoria desde jovem e, antes de ser capturado pela Gestapo, já a havia sistematizado em um livro que só não foi publicado devido a tal acontecimento. Inclusive, Frankl (2008) conta, no livro Em busca de sentido: um psicólogo no campo de concentração, que tentou permanecer - em vão - com esse primeiro manuscrito ("a obra de sua vida") durante sua estadia no campo.

É possível perceber que todas as categorias estão relacionadas entre si. A logoterapia e análise existencial dispõe de fundamentos teóricos - em especial sobre o sentido da vida - que suportam parcialmente a análise psicológica dos prisioneiros em seu cotidiano de horror. 
Nesta subseção, são destacados os aspectos mais relevantes da leitura, segundo os participantes da pesquisa. Tais aspectos estão reunidos na Tabela 2. As duas primeiras categorias mencionadas nesta tabela - "desumanidade" e "valores de vivência" - estão detalhadas, posteriormente, nas Tabelas 3 e 4. Embora as categorias estejam ordenadas em sentido decrescente, segundo suas respectivas frequências, elas não são apresentadas no texto necessariamente nessa ordem. Outro ponto relevante é que a partir daqui os sujeitos já começaram a fazer associações críticas com a sua realidade ou com a sua própria vida em particular, bem como, não raro, se colocaram no lugar dos prisioneiros.

A desumanização presente nos campos nazistas, em suas variadas facetas, foi o tópico mais comentado, com um total de 119 estudantes (67,2\%). Os resultados estão descritos na Tabela 3, em que as frequências relativas têm sempre como parâmetro esses 119 estudantes. A categoria "mundo subumano", referenciada por 40,1\% dos alunos, agrega a maioria desses aspectos desumanizadores, como más condições de habitação, serviço de saúde precário, falta de higiene, frio, humilhações, separação dos familiares, violência brutal, trabalho forçado, fome crônica, entre tantos outros. Enfim, trata da realidade desumanizadora dos campos de concentração. As demais categorias citadas estão de algum modo relacionadas a essa, porém foram mais citadas pelos estudantes.

\section{Tabela 2 - Categorias do que chamou mais a atenção dos sujeitos} na leitura (continua)

\begin{tabular}{|c|c|c|c|}
\hline Categoria & FrA & FrR & Exemplo \\
\hline Desumanidade & 119 & $67,2 \%$ & Ver Tabela 3 \\
\hline $\begin{array}{l}\text { Valor de } \\
\text { vivência }\end{array}$ & 68 & $38,4 \%$ & Ver Tabela 4 \\
\hline $\begin{array}{l}\text { Vontade de } \\
\text { sentido }\end{array}$ & 36 & $20,3 \%$ & $\begin{array}{l}\text { A busca de sentido é o que motiva pessoas } \\
\text { a suportarem, cada vez mais, a sua } \\
\text { sobrevivência. (d10) } \\
\text { Outro aspecto interessante é a ideia de que } \\
\text { o prisioneiro deve se apegar a alguém ou } \\
\text { a alguma coisa no futuro como requisito } \\
\text { para sobreviver, pois se não o fizesse } \\
\text { era provável que entregasse os pontos } \\
\text { devido as condições extremas do campo de } \\
\text { concentração. (e22) } \\
\text { Um pensamento que me ocorreu ao ler o } \\
\text { livro é procurar fazer uma reflexão sobre a } \\
\text { minha vida, sobre o que quero e o que busco. } \\
\text { (e12) }\end{array}$ \\
\hline
\end{tabular}


Tabela 2 - Categorias do que chamou mais a atenção dos sujeitos na leitura

\begin{tabular}{|c|c|c|c|}
\hline & & & \\
\hline Categoria & FrA & FrR & Exemplo \\
\hline $\begin{array}{l}\text { Valor de } \\
\text { atitude }\end{array}$ & 32 & $18,1 \%$ & $\begin{array}{l}\text { O que mais surpreende nesses relatos é como } \\
\text { as pessoas conseguiam retirar seu melhor } \\
\text { mesmo na pior das situações. (e25) } \\
\text { Com efeito, a vida tem sentido, independente } \\
\text { das condições. (a20) } \\
\text { Quando se tem um propósito, superar as } \\
\text { adversidades da vida se torna muito mais } \\
\text { possível. Dessa forma, após a leitura concluí } \\
\text { que o melhor a se fazer quando enfrentamos } \\
\text { uma situação difícil é refletir por que estamos } \\
\text { passando por aquilo e encontrar um motivo } \\
\text { para continuar firme e de pé. (A13) }\end{array}$ \\
\hline Liberdade & 25 & $14,1 \%$ & $\begin{array}{l}\text { Situações vão provando que o limite humano é } \\
\text { algo impossível de ser medido. (d10) } \\
\text { Algo muito interessante mostrado no livro } \\
\text { através de alguns acontecimentos é que } \\
\text { apesar de sermos obrigados a suportar e } \\
\text { não podermos mudar situações exteriores, } \\
\text { interiormente falando somos sempre livres. } \\
\text { (d22) }\end{array}$ \\
\hline Libertação & 25 & $14,1 \%$ & $\begin{array}{l}\text { Achei que quando os prisioneiros fossem } \\
\text { libertos do campo, seriam tomados por um } \\
\text { sentimento de alegria muito grande (...) eles } \\
\text { desaprenderam a ser alegres e custou a } \\
\text { acreditar que estavam livres (...) Sonharam } \\
\text { tanto com a liberdade que agora não sabem } \\
\text { como lidar com ela, porque de certa forma } \\
\text { estavam acostumados a ficar presos e serem } \\
\text { "fantoches" nas mãos dos comandantes. (e31) } \\
\text { Alguns se tornaram violentos e queriam } \\
\text { descontar o sofrimento que passaram. (e8) }\end{array}$ \\
\hline
\end{tabular}

Fonte: Elaboração própria.

A apatia (ou embotamento afetivo), isto é, a perda da sensibilidade, foi citada por $44,5 \%$ dos estudantes. Tamanhas eram as atrocidades durante a guerra que ver alguém morto, por exemplo, já não mobilizava os prisioneiros emocionalmente. A eles apenas interessava aquilo que fazia sobreviver, era um mecanismo de defesa da pessoa (Frankl, 2003).

Essa realidade tão cruel dos campos de concentração era tão grande que, uma vez, Viktor Frankl deixou de acordar um companheiro que gemia e se revolvia em um evidente pesadelo, porque não poderia haver pesadelo maior que aquela realidade à qual eles estavam subjugados. Este fato foi citado por 20,2\% dos alunos. Até mesmo alguns companheiros de prisão se tornaram seus carrascos - os "capos" - quando se aliavam aos nazistas em troca de algumas vantagens. Também foi marcante para os 
estudantes a ilusão de indulto, que ocorria quando prisioneiros, diante de seu destino trágico, especialmente diante da morte iminente, pensavam, em vão, que ainda iria acontecer, no último momento, algo que os livraria de tal infortúnio.

Tabela 3 - (Sub)categorias da categoria desumanidade

\begin{tabular}{|c|c|c|c|}
\hline Categoria & FrA & FrR & Exemplo \\
\hline $\begin{array}{l}\text { Mundo } \\
\text { subumano }\end{array}$ & 71 & $40,1 \%$ & $\begin{array}{l}\text { Ao final do dia deitar sobre uma tábua, dividindo } \\
\text { até com } 9 \text { pessoas o espaço de uma, usando apenas } \\
\text { dois cobertores (d10) / todos ficaram bastantes } \\
\text { desesperados por não verem mais a própria } \\
\text { família, amigos, etc. (d18) / não existia nenhuma } \\
\text { mínima higiene (d32) / os cuidados médicos } \\
\text { eram feitos de modo inadequado (d8) / o medo } \\
\text { perceptível de muitos à espera de crematórios ou } \\
\text { câmaras de gás (f31) / utilizar a mesma camisa } \\
\text { por meses. (g35) }\end{array}$ \\
\hline Apatia & 53 & $44,5 \%$ & $\begin{array}{l}\text { Chamou-me muito a atenção o fato de o indivíduo } \\
\text { não mais se sensibilizar diante das várias cenas } \\
\text { de crueldade que presencia seus companheiros } \\
\text { sofrendo diariamente. Foi a partir disso que } \\
\text { percebi quão corriqueiras e repetitivas eram tais } \\
\text { situações para que as tornassem triviais. (g35) }\end{array}$ \\
\hline Pesadelo & 24 & $20,2 \%$ & $\begin{array}{l}\text { Esse parágrafo foi, em minha opinião, a síntese de } \\
\text { toda a descrição dos campos de concentração. (...) } \\
\text { tudo o que eu consegui pensar foi: "A que ponto } \\
\text { temos que chegar, para acharmos um pesadelo } \\
\text { melhor do que a realidade?". Nesse momento } \\
\text { eu tive um entendimento concreto do que foi a } \\
\text { experiência do campo de concentração. (d25) }\end{array}$ \\
\hline Capos & 12 & $10,1 \%$ & $\begin{array}{l}\text { Ele diz que os capos, em várias ocasiões, eram mais } \\
\text { rigorosos se comparados aos guardas, chegando } \\
\text { a bater com mais violência que a SS. Isso chamou } \\
\text { minha atenção do ponto de vista de que eles eram } \\
\text { o mesmo povo que sofria, que foi aprisionado e em } \\
\text { algum momento morreria na câmara de gás. (a4) } \\
\text { O que mais impressiona nesses indivíduos é o fato } \\
\text { de que mesmo após vivenciar as faces mais duras } \\
\text { daquele regime, conseguiam, ainda, ser algozes } \\
\text { dos seus "companheiros". (d33) }\end{array}$ \\
\hline $\begin{array}{l}\text { Ilusão de } \\
\text { indulto }\end{array}$ & 12 & $10,1 \%$ & $\begin{array}{l}\text { Um primeiro aspecto que mais me chamou } \\
\text { atenção no livro foi a ilusão de indulto, onde eu } \\
\text { me identifiquei bastante e reconheci que mesmo } \\
\text { em situações de desespero, tristeza e de certa } \\
\text { forma condenação sempre vamos nos iludir no } \\
\text { momento com alguma esperança de uma "luz no } \\
\text { fim do túnel". (g33) }\end{array}$ \\
\hline
\end{tabular}

Fonte: Elaboração própria. 
Apesar das atrocidades mencionadas, é perceptível nos relatórios como os estudantes se surpreendem e destacam a força de superação do ser humano mediante o sentido na vida. Para ser mais exato, Frankl denomina isso de força desafiadora do espírito - ou força do antagonismo noopsíquico -, quando a pessoa "toma uma posição perante o adoecimento psicofísico, e, em verdade, uma posição extremamente significativa" (Frankl, 2012, p. 98) e consegue superar limites antes inimagináveis. Frankl (2008, p. 31) chega a afirmar que, a partir da experiência dos campos de concentração, "quem é ligado à medicina aprende sobretudo uma coisa: os compêndios mentem", porque justamente se via nesses campos o contrário do que os compêndios afirmavam na época, por exemplo, como era impossível ficar sem dormir uma determinada quantidade de horas. A vontade de sentido foi, portanto, percebida como força motivacional do ser humano, como pôde ser observado por 20,3\% dos sujeitos (Tabela 2). Esse sentido podia ser traduzido como "um alvo no futuro (...) algo que os sustentava, e geralmente se tratava de um pedaço de futuro" (Frankl, 2008, p. 97). Isso fez com que alguns dos próprios estudantes se inquietassem sobre o sentido presente em suas vidas, percebendo que a vida sempre espera algo deles.

Nesse contexto, 38,4\% dos estudantes citaram valores vivenciais (Tabela 4), ou seja, situações em que os prisioneiros encontraram sentido experimentando algo ou amando alguém. Primeiramente, houve um sentimento relativamente comum de surpresa entre 51,5\% daqueles que falaram dos valores vivenciais. Eles se surpreenderam com o fato de haver arte, como teatro e música, no campo de concentração, ou mesmo de os prisioneiros fazerem piadas lá. Além disso, o amor por outra pessoa também foi destacado como capaz de mobilizar forças nos prisioneiros. Finalmente, os estudantes destacaram a bondade, fosse aquela presente nos prisioneiros que eram solidários a outros, fosse em alguns poucos soldados nazistas que doavam itens importantes para a sobrevivência. Outros 18,1\% falaram dos valores atitudinais, do quanto os prisioneiros conseguiam extrair algo positivo do sofrimento. Ademais, eles extraíram dos exemplos dos prisioneiros reflexões para suas vidas.

\section{Tabela 4 - (Sub)categorias da categoria valores vivenciais}

\begin{tabular}{|c|c|c|c|}
\hline Categoria & FrA & FrR & Exemplo \\
\hline Humor e arte & 35 & $51,5 \%$ & $\begin{array}{l}\text { Quando o autor narra que havia momentos } \\
\text { de lazer, em que os prisioneiros organizavam } \\
\text { teatros improvisados e faziam piadas sobre } \\
\text { suas próprias más condições, isso é um fato } \\
\text { que surpreende ao leitor, saber que, mesmo } \\
\text { sob condições deploráveis (...) ainda eram } \\
\text { capazes de conseguir se divertir, mesmo que } \\
\text { minimamente. (d19) } \\
\text { Me impressiona a capacidade que eles têm } \\
\text { de conseguir rir em algum momento em um } \\
\text { campo de concentração mesmo de forma } \\
\text { momentânea. (a4) }\end{array}$ \\
\hline
\end{tabular}


Tabela 4 - (Sub)categorias da categoria valores vivenciais

\begin{tabular}{|c|c|c|c|}
\hline Categoria & FrA & FrR & Exemplo \\
\hline Amor & 22 & $32,4 \%$ & $\begin{array}{l}\text { O autor, baseado em suas marcantes } \\
\text { experiências mostra que este sentimento é o } \\
\text { bem mais precioso que pode ser alcançado. } \\
\text { Após todo o sofrimento do prisioneiro, o amor } \\
\text { se torna o último capaz de mantê-lo em pé e } \\
\text { fazê-lo seguir em frente. (e23) } \\
\text { Ao pensar na sua mulher, por mais esgotado } \\
\text { que esteja, pensar na sua amada, lhe concebe } \\
\text { forças para superar os desafios rotineiramente. } \\
\text { (e32) }\end{array}$ \\
\hline Bondade & 17 & $25,0 \%$ & $\begin{array}{l}\text { Havia também guardas que eram mais } \\
\text { "humanos" e ajudavam os presos, seja dando } \\
\text { remédios ou até mesmo alimento e agasalho, } \\
\text { por mais raro que aquilo fosse. (e11) } \\
\text { Alguns prisioneiros mesmo em uma condição } \\
\text { terrível, ainda eram generosos o suficiente } \\
\text { para ajudar alguém, isso nos dá esperança em } \\
\text { relação a humanidade das pessoas. (e26) }\end{array}$ \\
\hline
\end{tabular}

Fonte: Elaboração própria.

Outras duas categorias relacionam-se ao tema da liberdade. A primeira trata da liberdade interior, uma mensagem enfática no livro e um dos pilares da logoterapia. O prisioneiro, apesar de sua condição, ainda é capaz de decidir o que faz a partir disso e até mesmo de superar a fragilidade de seu psicofísico. Já a segunda categoria é a liberdade concretizada no momento da libertação. Nesse ponto, acontece algo que foi surpreendente para os leitores universitários: os prisioneiros não se sentem alegres e não sabem lidar com a liberdade e com a possibilidade de reconstrução da vida. Eles permanecem, em alguma medida, presos àquilo que viveram nos campos de concentração. Pior, alguns se sentem no direito de praticar injustiças por terem sido vítimas de tantas delas.

\section{O que os alunos mais aprenderam a partir da leitura}

Esta seção destaca o que estudantes conseguiram extrair de aprendizado a partir da leitura realizada. Entre outras coisas, estão presentes discussões acerca de ideias do autor, reflexões pessoais sobre a vida, comparações críticas com a realidade, seja a universidade, seja a sociedade como um todo. A Tabela 5 reúne as principais categorias e alguns trechos das redações.

Os estudantes perceberam a importância do sentido da vida como fator motivador, até mesmo no sofrimento, atuando como fator de resiliência. Em outras palavras, isso significa ter metas na vida e nas situações, ter uma perspectiva de futuro, algo que ajude a não desistir dos sonhos 
ou objetivos, por mais que pareçam difíceis. Essa vontade de sentido também foi manifestada por meio dos questionamentos existenciais que os estudantes fizeram sobre o sentido da vida. A leitura provocava isso. Essa categoria de vontade de sentido foi citada por $36,7 \%$ dos estudantes.

Outro aprendizado significativo, mencionado por $35 \%$ dos alunos, foi alcançado a partir da discussão sobre os valores atitudinais vividos pelos prisioneiros. Os estudantes comentaram que se pode amadurecer a partir do sofrimento: não se deve deixar abater ou rechaçá-lo de imediato, mas deve-se refletir e procurar um aprendizado e/ou um sentido a partir dele.

\section{Tabela 5 - Categorias do que os sujeitos mais aprenderam a partir da leitura}

(continua)

\begin{tabular}{|c|c|c|c|}
\hline Categoria & FrA & FrR & Exemplo \\
\hline $\begin{array}{l}\text { Vontade de } \\
\text { sentido }\end{array}$ & 65 & $36,7 \%$ & $\begin{array}{l}\text { O livro me fez refletir bastante sobre qual o } \\
\text { sentido em tudo que eu faço, e como as minhas } \\
\text { ações e meu dia a dia vão completar esse sentido, } \\
\text { a logoterapia me trouxe uma visão mais poética } \\
\text { de como eu trato a minha vida e de como eu } \\
\text { enxergo o mundo. (...) questionamento do } \\
\text { por que e pra que eu existo veio à tona várias } \\
\text { vezes enquanto lia o livro e o fato de não } \\
\text { saber a resposta tornava algo absurdamente } \\
\text { perturbador, o que me fez buscar um tempo para } \\
\text { permitir-me auto conhecer. (f36) } \\
\text { A experiência com este livro me trouxe mais } \\
\text { calma e esperança sobre a vida, principalmente } \\
\text { se tratando da Universidade, pois já estou } \\
\text { enfrentando os primeiros problemas não só nas } \\
\text { disciplinas, mas também na minha adaptação } \\
\text { a uma cidade diferente e a uma vida longe dos } \\
\text { meus pais. Durante a leitura fiz as mesmas } \\
\text { reflexões que Viktor fazia dentro do campo } \\
\text { quase que automaticamente. Perceber que eu } \\
\text { tenho vários motivos para fazer o que faço e } \\
\text { pensar que o mundo realmente espera coisas de } \\
\text { mim foi renovador. (a13) }\end{array}$ \\
\hline $\begin{array}{l}\text { Valor de } \\
\text { atitude }\end{array}$ & 62 & $35,0 \%$ & $\begin{array}{l}\text { Outro fator que pode nortear a nossa vida é que } \\
\text { o sofrimento também pode nos ajudar a sermos } \\
\text { mais fortes diante das situações delicadas. (d28) } \\
\text { Muitas vezes não pensamos no real objetivo } \\
\text { daquele sofrimento, apenas sofremos esperando } \\
\text { que um dia o mesmo acabe. No livro é } \\
\text { estimulada uma reflexão sobre isso. A história } \\
\text { do personagem mostra que mesmo nos piores } \\
\text { tormentos que uma pessoa pode passar, ao se } \\
\text { dar sentido ao sofrimento, é possível passar por } \\
\text { ele de cabeça erguida. (g20) }\end{array}$ \\
\hline
\end{tabular}


Tabela 5 - Categorias do que os sujeitos mais aprenderam a partir da leitura

\begin{tabular}{|c|c|c|c|}
\hline Categoria & FrA & FrR & Exemplo \\
\hline $\begin{array}{l}\text { Valor de } \\
\text { vivência }\end{array}$ & 57 & $32,2 \%$ & Ver Tabela 6 \\
\hline $\begin{array}{l}\text { Valorizar } \\
\text { o que é } \\
\text { essencial }\end{array}$ & 41 & $23,2 \%$ & $\begin{array}{l}\text { Esse trecho me fez refletir que devo dar valor } \\
\text { às pequenas coisas do dia a dia, um abraço nos } \\
\text { pais, um bom dia a um amigo ou até mesmo a } \\
\text { um desconhecido, apreciar a natureza, etc. São } \\
\text { essas pequenas coisas que mudam nossa vida } \\
\text { como um todo. (d9) } \\
\text { Me fez dar mais valor à vida que tenho e } \\
\text { reclamar menos dos meus problemas, pois me } \\
\text { sentia incomodado com qualquer coisa que saía } \\
\text { da rotina. A partir da leitura do livro, comecei } \\
\text { a olhar com outros olhos para as coisas simples } \\
\text { da vida. (g14) } \\
\text { Nós que vivemos em ótimas circunstâncias em } \\
\text { relação a eles, devíamos até agradecer todos os } \\
\text { dias pelo que somos e pelo que temos. Não estou } \\
\text { dizendo para nos conformarmos com pouco, mas } \\
\text { estou dizendo para sermos mais gratos por cada } \\
\text { pequeno detalhe na nossa vida. (e1) } \\
\text { Às vezes colocamos coisas fúteis sobre o } \\
\text { que realmente importa. Pensando muito mais } \\
\text { no futuro e esquecendo o que nos rodeia no } \\
\text { presente e só damos valor quando perdemos ou } \\
\text { nos distanciamos. (f25) }\end{array}$ \\
\hline Liberdade & 23 & $13,0 \%$ & $\begin{array}{l}\text { Pude compreender que a vida é cheia de opções } \\
\text { e existem dois modos que lidamos com ela. O } \\
\text { primeiro modo é sentar, chorar e reclamar por } \\
\text { ter desistido de correr atrás dos sonhos e desejos } \\
\text { pois apresentaram obstáculos e empecilhos (...) } \\
\text { e o segundo é encarar toda dificuldade, é cair e } \\
\text { levantar novamente para tentar outra vez, se } \\
\text { tornar forte e aguentar os duros socos que a } \\
\text { vida te dá. (g22) } \\
\text { Aprende-se com isso que por mais terrível que } \\
\text { seja a situação, existe sempre a possibilidade } \\
\text { de fazer diferente, de reagir com liberdade } \\
\text { (...) Mesmo sendo muito difícil, a pessoa } \\
\text { interiormente pode ser mais forte do que seu } \\
\text { destino exterior. (e31) }\end{array}$ \\
\hline
\end{tabular}


Tabela 5 - Categorias do que os sujeitos mais aprenderam a partir da leitura

(conclusão)

\begin{tabular}{|c|c|c|c|}
\hline Categoria & FrA & FrR & Exemplo \\
\hline $\begin{array}{l}\text { Responsa- } \\
\text { bilidade }\end{array}$ & 22 & $12,4 \%$ & $\begin{array}{l}\text { Me levou a uma meditação sobre as coisas } \\
\text { que tenho negligenciado na minha vida, todo } \\
\text { sofrimento que tenho deixado esquecido, que } \\
\text { tenho delegado a outros resolver. (g17) } \\
\text { Minha percepção sobre a vida era bastante } \\
\text { rasa em relação a profundidade a qual o autor } \\
\text { considera seus pensamentos sobre o assunto. } \\
\text { Por meio do livro (...) hoje eu sei que devo } \\
\text { questionar menos a respeito do que eu espero da } \\
\text { vida e pensar mais no que a vida espera de mim, } \\
\text { assim aproveitar cada dia da minha existência e } \\
\text { fazer valer a pena a minha vida. (a18) }\end{array}$ \\
\hline
\end{tabular}

Fonte: Elaboração própria.

Os valores vivenciais também foram destacados por 32,2\% dos alunos. Mais uma vez, humor, arte, amor e bondade figuraram entre os temas mais debatidos (Tabela 6). A arte e o humor foram citados como recursos para se distanciar do sofrimento, para aliviá-lo, esquecê-lo um pouco, ou mesmo para encontrar uma solução. O amor foi evidenciado, sobretudo, como força propulsora do ser humano para vencer desafios até mesmo inimagináveis. A importância da bondade na sociedade foi destacada pelos sujeitos, que perceberam que ela pode ser encontrada em qualquer grupo de pessoas, como naqueles presos que abdicavam da sua preciosa lasca de pão ou naqueles guardas que davam pães.

\section{Tabela 6 - (Sub)categorias da categoria valores vivenciais}

\begin{tabular}{|c|c|c|c|}
\hline Categoria & FrA & FrR & Exemplo \\
\hline Amor & 28 & $49,1 \%$ & $\begin{array}{l}\text { A força que o amor tem de impulsionar pessoas } \\
\text { a realizar coisas inimagináveis e sair de situações } \\
\text { completamente adversas e sofridas. E de suma } \\
\text { importância ter alguém para se guiar, uma imagem } \\
\text { para se apoiar, seja da mãe, do pai, de uma paixão, ou } \\
\text { do seu Deus, é isso que te faz ter um sentido para viver } \\
\text { e buscar por aquilo que deseja. (f30) } \\
\text { De forma resumida, o amor é capaz de trazer sentido, } \\
\text { mesmo em situações que não façam sentido nenhum. } \\
\text { (a2) }\end{array}$ \\
\hline
\end{tabular}


Tabela 6 - (Sub)categorias da categoria valores vivenciais

\begin{tabular}{|c|c|c|c|}
\hline Categoria & FrA & FrR & Exemplo \\
\hline Humor e arte & 16 & $28,1 \%$ & $\begin{array}{l}\text { Eu mesmo faço isso. Quando algo ruim acontece, } \\
\text { costumo combater isso com humor. Faço piadas, } \\
\text { como se isso amenizasse a coisa. E ameniza. As vezes } \\
\text { é importante rir das dores. Enfrentar uma situação de } \\
\text { cabeça erguida sempre é algo positivo. (e7) } \\
\text { Retomando a parte da arte nos campos de concentração, } \\
\text { pude perceber que em momentos de pouca esperança, } \\
\text { minha reação é me entristecer de forma totalmente } \\
\text { visível. Assim, não consigo enxergar além do } \\
\text { problema vivido. Muitas vezes, quando há um conflito } \\
\text { acontecendo, eu não sou capaz de resolver outras } \\
\text { coisas até esse conflito ser solucionado. Essa parte } \\
\text { do livro onde fala que os prisioneiros se reuniam para } \\
\text { cantar, apresentar peças, entre outras coisas fez-me } \\
\text { refletir que devo dar espaço para outras coisas em } \\
\text { períodos de aflição. Às vezes para esquecer ou até } \\
\text { mesmo achar uma possível solução. (a4) }\end{array}$ \\
\hline Bondade & 14 & $24,6 \%$ & $\begin{array}{l}\text {... foi o das pessoas que tentavam trazer bondade no } \\
\text { local, com um pouco de alimento e os guardas que às } \\
\text { vezes usavam seu próprio dinheiro para tentar ajudar } \\
\text { os presos. Isso mostrou que nem todos os presos são } \\
\text { bons e nem todos guardas são ruins, e isso acontece } \\
\text { no cotidiano já que muitas vezes aquelas pessoas que } \\
\text { pensamos ser ruins na verdade estão querendo ajudar } \\
\text { e as que pensamos ser boas querem prejudicar. (e11) }\end{array}$ \\
\hline
\end{tabular}

Fonte: Elaboração própria.

Algo interessante suscitado pelos estudantes foi a valorização do que é essencial para eles ao se depararem com tamanha privação dos prisioneiros. Isso se desdobra em dois aspectos. Primeiro, os sujeitos se dão conta do valor de elementos cotidianos da vida, que inclusive influenciam na formação da própria subjetividade. Percebem que os problemas enfrentados parecem até "bobos" ou, no mínimo, não tão complexos como se pensava, não são os maiores do mundo. Segundo, há uma valorização do que se tem - ao invés do que não se tem -, seja de pessoas importantes, seja de itens materiais. Nota-se aqui uma espécie de mudança para um olhar mais positivo diante das possibilidades da existência.

Finalmente, a liberdade e a responsabilidade também ressaíram das falas dos participantes. Primeiro, eles destacaram a capacidade do ser humano de fazer escolhas, mesmo diante de obstáculos extremos. Tais obstáculos podem influenciar, até mesmo de uma forma profunda, mas jamais determinar totalmente o ser humano. Segundo, a responsabilidade foi compreendida, pelos alunos, na percepção posta pelo autor, a qual consiste em assumir as rédeas da sua própria existência e responder às perguntas que a vida faz por meio das mais diversas situações. Alguns sujeitos demonstraram se conscientizar de que são protagonistas de suas existências. 
Os sujeitos citaram muitos trechos do livro de forma direta (Frankl, 2008). Então, identificamos os três mais citados:

1) "Quem tem por que viver aguenta quase todo como." (Frankl, 2008, p. 101), trecho mencionado por $10,2 \%$ dos estudantes. Uma frase atribuída a Nietzsche, por Frankl, para falar do valor motivacional da vontade de sentido. Inclusive um sujeito afirmou que "esta frase esteve constantemente presente em minhas corridas matinais durante todas as férias" (e16);

2) "Nunca e jamais importa o que nós ainda temos a esperar da vida, mas sim exclusivamente o que a vida espera de nós." (Frankl, 2008, p. 102), frase mencionada por $8,5 \%$ dos participantes. Aqui está retratada a consciência do ser-responsável da pessoa que responde aos questionamentos da vida;

3) "Nem mesmo o sonho mais terrível poderia ser tão ruim como a realidade que nos cercava ali naquele campo." (Frankl, 2008, p. 45), destacado por $7,9 \%$ dos alunos. Este último trecho remete à situação em que Frankl pensou em acordar um companheiro de seu pesadelo.

Na avaliação da disciplina, a taxa de resposta estimada foi de $58,8 \%$. A atividade do relatório e o interesse pelo livro foram avaliados com 4,08 $( \pm 0,95)$ e 4,12 ( $\pm 1,0)$ pontos, respectivamente, em uma escala de 1 a 5 . Isso demonstra que a atividade foi significativa para os sujeitos. Porém, na questão sobre a cobertura de leitura, obteve-se os seguintes dados: $55,8 \%$ dos alunos leram o livro na íntegra ou 80\% dele, no mínimo; $21,1 \%$ leram aproximadamente $60 \%$; e 21,1\% menos da metade ou quase nada. É importante lembrar que esse item foi questionado apenas nas duas últimas turmas, com taxa de resposta estimada de $74,3 \%$. De todo modo, não deixa de expressar uma amostra considerável sobre o todo. De fato, em alguns trabalhos fica perceptível a leitura superficial, especialmente quando seus escritos se detêm apenas nas páginas iniciais do livro. Por outro lado, por falta de atenção ou interesse, alguns alunos também extrapolaram o escopo da leitura, adentrando em outras duas partes do livro que tratam de introduções da logoterapia e análise existencial. Isso fica evidente na leitura das redações, quando, por exemplo, um deles comenta que a tríade trágica, terminologia exclusiva das partes mencionadas, "contribuiu muito no meu pensamento de enfrentar as dificuldades da vida, mesmo com dor ou algo negativo, sempre seguir em frente" (d4).

\section{Discussão e conclusão}

O presente trabalho dedicou-se a analisar as percepções de universitários calouros acerca de questões sobre o livro Em busca de sentido, de Viktor Frankl. Apesar de todo quadro de horror descrito, em 
geral, a maioria dos estudantes foi capaz de se conectar com a mensagem central do livro que gira sobre uma questão motivacional: "a busca do indivíduo por um sentido é a motivação primária em sua vida" (Frankl, 2008, p. 124). Nas ideias centrais do livro, eles perceberam que muito mais do que narrar o cotidiano pavoroso dos prisioneiros, o autor desejava demonstrar a origem da força de resistência deles, que desafiava seus psicofísicos, debilitados em condições subumanas, a resistir. Assim, não foi apenas a desumanidade presente nos campos de concentração, em seus diversos detalhes e facetas, o que mais chamou a atenção dos estudantes, mas também como os desumanizados lutavam para se humanizar, buscando fazer emergir o que havia de mais humano neles, como a arte, o humor, o amor, a generosidade, a realização, a liberdade, entre outros aspectos. Houve de fato uma luta feroz pela sobrevivência, mas também houve uma luta profundamente árdua para manter a dignidade. Frankl (2008, p. 90) cita uma frase de Dostoiévski que tenta resumir isso: "Temo somente uma coisa: não ser digno do meu tormento.". Na verdade, esse é o diferencial do livro. Para Bruzzone (2011), o relato frankliano se distingue dos demais testemunhos de intelectuais judeus, porque não se restringiu a descrever como as pessoas eram sistematicamente exterminadas e porque buscou compreender e ressaltar como alguns foram capazes de resistir e manter sua dignidade perante tamanha violência.

Não por acaso, os principais aprendizados discutidos pelos sujeitos decorreram desse mote. Eles demonstraram compreender a importância vital de se ter um sentido, ou seja, um objetivo na vida, algo concreto para realizar a partir das situações vividas. Alguns sentiram-se inclusive provocados a questionar o sentido de suas vidas - algo genuinamente humano e salutar -, explicitando até mesmo uma necessidade de silenciar para refletir melhor. Outros estudantes perceberam que, na verdade, é a vida que pergunta, "experimentamos a nós mesmos como os indagados, como aqueles aos quais a vida dirige perguntas diariamente e a cada hora - perguntas que precisamos responder (...) através da ação" (Frankl, 2008, p. 101). A responsabilidade está associada a essa capacidade de responder aos acontecimentos da vida. As respostas são dadas - ou a pessoa é responsável - porque é livre para decidir interiormente, porque existe uma liberdade (Frankl, 2003), outra categoria ressaltada. Mesmo que possua uma liberdade limitada diante de condicionantes, o ser humano pode decidir sua atitude, pode se autoconfigurar, ou seja, sempre haverá escolhas. Esse é o "de que" da liberdade, daquilo que a pessoa pode se libertar, e o seu "para que" é a responsabilidade (Frankl, 2007). Desse modo, nota-se um processo importante de conscientização do ser-responsável e do ser-livre.

Outro ponto significativo foi o dos valores decorrentes de atitudes perante o sofrimento imutável. Em uma sociedade líquida, em que o sofrimento é evitado a todo custo (Bauman, 2008), salta aos olhos dos estudantes que o sofrimento (inevitável) pode ter um valor e/ou aprendizado. A pessoa pode crescer por meio dele, pode "transformar criativamente os aspectos negativos da vida em algo positivo ou construtivo (...), tirar o melhor de cada situação" (Frankl, 2008, p. 161). Ademais, diante da finitude da vida, é comum se inquietar com questões existenciais. Visto que o texto trata desse tema de algum modo, os estudantes também despertaram para a valorização daquilo que é mais importante para eles, desde elementos 
cotidianos simples até pessoas queridas. Entenderam que é renovar o olhar para aquilo que tem valor, aquilo que tem sentido na vida; sair de si mesmo para se dedicar a algo ou alguém.

A leitura superficial sinalizada por parte dos sujeitos impôs um limite na pesquisa, já que não foi possível elaborar uma análise com base na leitura integral de todos, o que poderia fazer com que frequências atuais mudassem ou que novas categorias emergissem. Outra limitação foi a de que os textos podem não refletir exatamente a profundidade e/ou intensidade como a mensagem do autor chegou aos sujeitos. Por exemplo, quando um aluno diz que a partir da leitura "percebeu que", não sabemos até que ponto essa percepção se efetivou de fato e se prolongou no tempo. Notou-se, ainda, que foram realizadas algumas apropriações conceituais equivocadas, o que consideramos natural de certo modo, já que os sujeitos não dominam a teoria frankliana. Por essas razões, a atividade desenvolvida é apenas um ponto de partida para propor outras atividades. Nesse contexto, trabalhos futuros pretendem realizar uma avaliação que contemple toda a sequência didática de atividades em torno do tema "sentido de vida".

Não foram todos os estudantes, evidentemente, que abordaram todas as categorias aqui debatidas, mas é fundamental lembrar que estamos discutindo as temáticas mais comuns suscitadas. De todo modo, os estudantes refletiram, discutiram e aprenderam sobre sentido e valores, especialmente, os vivenciais e atitudinais. Desse modo, esta pesquisa contribui para o campo educacional ao propor atividades que suscitem a formação humana e o aprendizado humanístico-existencial entre os educandos, inclusive promovendo e questionando o sentido de vida. Estimular os jovens a se engajarem em uma vida significativa - e saber como promover isso no contexto educacional - tem despertado o interesse crescente de pesquisadores ao redor do mundo (Malin, 2018; Moran, 2016; Siwek; Oleszkowicz; Słowińska, 2017). Portanto, outra contribuição desta pesquisa é a abordagem da realidade brasileira, mesmo com escopo pontual. Ademais, o presente trabalho explicita, ainda, por meio da avaliação realizada, o interesse e a receptividade dos estudantes a essa temática, o que revela a importância de se investir mais em pesquisas nessa área.

\section{Referências}

ALLPORT, G. W. Prefácio. In: FRANKL, V. E. Em busca de sentido: um psicólogo no campo de concentração. Petrópolis: Vozes, 2008. p. 5-7.

BARDIN, L. Análise de conteúdo. Lisboa: Edições 70, 2000.

BAUMAN, Z. A arte da vida. Rio de Janeiro: Zahar, 2008. 
BELLOMO, S. Valores, motivación y sentido: aportes de la teoría de Viktor Frankl a la práctica educativa. In: PINTOS, C. G. (Ed.). Frankl comentado. Buenos Aires: San Pablo, 2011. p. 104-124.

BRUZZONE, D. Afinar la conciencia: educación y búsqueda de sentido a partir de Viktor Frankl. Buenos Aires: San Pablo, 2011.

DEL RIO, G. En busca de sentido en el aula con Viktor Frankl: propuesta de actividades para adolescente en la escuela a partir del libro El Hombre en Busca de Sentido. Buenos Aires: San Pablo, 2013.

FRANKL, V. E. Psicoterapia para todos: uma psicoterapia coletiva para contrapor-se à neurose coletiva. Petrópolis: Vozes, 1990.

FRANKL, V. E. Psicoterapia e sentido da vida. São Paulo: Quadrante, 2003.

FRANKL, V. E. Um sentido para a vida: psicoterapia e humanismo. São Paulo: Idéias \& Letras, 2005.

FRANKL, V. E. A presença ignorada de Deus. São Leopoldo: Sinodal; Petrópolis: Vozes, 2007.

FRANKL, V. E. Em busca de sentido: um psicólogo no campo de concentração. Petrópolis: Vozes, 2008.

FRANKL, V. E. O que não está escrito nos meus livros: memórias. São Paulo: É Realizações, 2010.

FRANKL, V. E. A vontade de sentido: fundamentos e aplicações da logoterapia. São Paulo: Paulus, 2011.

FRANKL, V. E. Logoterapia e análise existencial: textos de seis décadas. Rio de Janeiro: Forense Universitária, 2012.

GARCÍA, L. A. La logoterapia es más que una terapia: hacia una propuesta educativa. Revista Mexicana de Logoterapia, Ciudad de México, 6 jun. 2009. Disponível em: <http://www.logoterapia.com.mx/ publicaciones/revista-mexicana-logoterapia/logoterapia-es-que-terapiahacia-propuesta-educativa >. Acesso em: 10 jan. 2019.

HERRERA, L. G. P. Viktor E. Frankl y su dictado de 1945: un psicólogo en el campo de concentración. Buenos Aires: San Pablo, 2015.

LUKAS, E. Histórias que curam porque dão sentido à vida. Campinas: Verus, 2005.

MALIN, H. Teaching for purpose: preparing students for lives of meaning. Cambridge: Harvard Education Press, 2018. 
MIGUEZ, E. M. Educação em busca de sentido: pedagogia inspirada em Viktor Frankl. São Paulo: Paulus, 2014.

MORAN, S. What do teachers think about youth purpose? Journal of Education for Teaching, Stanford, v. 42, n. 5, p. 582-601, Sept. 2016.

PINTOS, C. G. A logoterapia em contos: o livro como recurso terapêutico. São Paulo: Paulus, 1999.

SIWEK, Z.; OLESZKOWICZ, A.; SŁOWIŃSKA, A. Values realized in personal strivings and motivation, and meaning in life in Polish university students. Journal of Happiness Studies, Berlin, v. 18, n. 2, p. 549-573, Apr. 2017.

Recebido em 23 de maio de 2018.

Aprovado em 27 de novembro de 2018. 